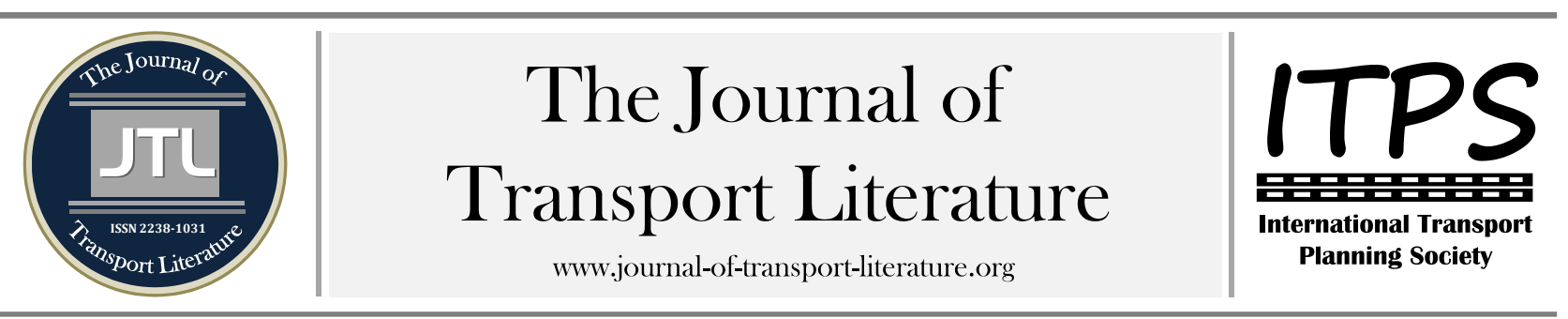

\title{
Social, technical-economic, environmental and political assessment for the evaluation of transport modes for petroleum products
}

Dante Bachi Junior; Geraldo Lucio Tiago Filho; Maria Rachel Russo Seydell ${ }^{+}$

Universidade Federal de Itajubá UNIFEI, Itajubá, Brasil

\section{Article Info}

Keywords:

petroleum products

sustainable transport

complete costs

railway

ducts

Submitted 28 Dec 2014;

received in revised form 22 Jun 2015

accepted 12 Jul 2015.

Licensed under

Creative Commons

CC-BY 3.0 BR.

\section{Abstract}

Distribution becomes the main link in a supply chain when transport efficiency is concerned. Being a huge size country, transport related problems in Brazil should be treated through the application of new information technology and more efficient logistic tools. This paper evaluates ducts and railway modes by the complete cost methodology to find the best alternative for the transportation of petroleum derived products, in a Case Study. The method deals with technical, economic, environmental, social and political factors being equally important, following the concepts of sustainable development. In general, only aspects related to investment, construction, equipment acquisition and financial return have been considered, which is inadequate for the effective functioning of a project. If only construction financial costs were concerned, the best alternative for the transportation of petroleum products would be the railway. However, the Complete Cost analysis shows that ducts are more advantageous with the highest valuation factors $(291,54$ points) versus the railway $(257,83$ points). Therefore, this study contributes to a more effective evaluation and discussion about the important aspects to be evaluated in making a choice for the most sustainable transport mode.

+ Corresponding author. Av. BPS, 1303, Pinheirinho, Itajubá - MG, 37500-903, Brasil.

E-mail address: rachelrusso99@gmail.com.

\section{Introduction}

This paper presents a Case Study for the evaluation of ducts and railway modes by the complete cost methodology, to find the best alternative for the transport of petroleum derived products. In the context of this study, the environment, the users, the social implications and policy decisions become crucial in the analysis of resources.

Operational efficiency and cost reduction in manufacturing and distribution is essential to obtain competitive advantage. Openness meant a need for restructuring of logistics, integrating to the global market with products being purchased from any part of the world, hiring international transport and warehousing and distribution for final consumers. In a continental sized country like Brazil, intensive application of new information technologies and more efficient logistic tools are necessary, so that the supply chain can be definitely integrated. In the case of the fuel market, the following may be considered members of the supply chain: carriers (rail, pipeline, roads or waterways), producers (Petrobras company, private refineries and petrochemical plants), distributors (Shell, Texaco, Esso Cosan, BR, Ipiranga etc.) and consumers (industries, retailers, individuals) (Soares, Leal and Azevedo, 2003). Inventories of refined products come from the refineries. Subsequently, according to the referred authors, the products are transported (by ducts or ships) to the Primary Bases, then to the Secondary Bases and to the various distribution companies in the Brazilian market. Transfers between facilities of Primary and Secondary Bases are mostly done by road transport (tankers) and rail transport (tank wagons).The Energy Resources Integrated Planning is a methodological tool that, in addition to the short, medium and long term energy planning, it helps decision making in the search of better uses for energy resources in a given region, considering the largest number of variables and parameters involved in a systemic, holistic and rational analysis. The goal to be achieved by the Complete Cost tool, which is part of the Integrated Planning Resources methodology, permeates areas of knowledge expressed by environmental, political, social and technical-economic dimensions and uses technical analysis and mathematical tools that configure its systemic character (Rigolin, 2013).

Section 1 presents a description of rail and pipeline transport modes, which are commonly used for petroleum products. Section 2 describes the characteristics of the complete cost analysis, with a brief description of the most important factors to be considered: technical-economic, environmental, social and political. Section 3 presents the research method: how to use the complete cost tool, the methodology for the analysis, the valuation of the factors through the use of different weights for the analysis elements and a numerical application with the equations used by the method. Section 4 presents the discussion of results for the case study - ducts transport mode and railway alternative. Conclusion section is based on the objectives and the case study analysis. The References list the papers and studies cited throughout the text.

\section{Modes of transport}

Railways have the ability to transport large volumes with high energetic efficiency, especially at medium and long distances. Furthermore, when compared to road transport, the improved safety records the lowest rate of accidents and 
robbery. Silva (2004) comments that Brazilian rail network is the largest in Latin America in terms of cargo, having reached, in 2001, 162.2 billion TKU. It is concentrated in the south, southeast and northeast and reaches part of the centre-west and north of the country, totalling 29,706 km. These are the typical loads: steel products, grain, iron, ore, cement, fertilizers, petroleum, limestone, coal and container freight. The 2001 Statistical Yearbook of Brazil Railways and the 2002 Annual Monitoring Report of Railway Concessions gather data about freight movement for each railroad and the characteristics of the networks. The studies include a total of 15 railways operating in 2000 and 11 operating in 2002. In these transactions, flows of oil in seven railroads have been recorded and there are no records of crude oil transport since 1997. America Latina Logistica (ALL) transported the largest amount in 2002, 2.5 million TEU (twenty-foot equivalent unit). In percentage terms, Northeast Railway Company is highlighted in the transport of oil of approximately $23.2 \%$ of the total cargo.

Among the land transport modes, the pipeline/duct is more economic for large volumes and high energy efficiency, since only the load moves. Ducts are considered the world safest transport mode for crude oil, carrying products to oil tankers, terminals and refineries. They can be classified as transfer or transport ducts, according to the function performed in the operations. Thus, the pipeline has several clients and transfer pipelines interest only to the same entity or possibly two distinct entities. The lines of derived products and alcohol are transportation lines because they meet the operative distributors bases, and petroleum are transfer lines with interest only to Petrobras. In Brazil, ducts are most used for gases and oil (Silva, 2004).

\section{Complete Cost analysis}

The Complete Cost analysis considers all factors involved in decision making towards sustainability: technical, economic, environmental, social and political factors with the same importance, satisfying the concepts of sustainable development and resource planning. The method includes the elements involved in an evaluation process, as well as the concern with the supply of future needs through the rational use of resources at the present time. This tool as a new concept revolutionizes the evaluation of a project feasibility, because only aspects related to investment, construction, equipment acquisition and financial return have traditionally been considered in analysis, shown inadequate for the effective functioning of an enterprise.

According to Boarati et al. (1999), the technical-economic factor reflects the vision of the entrepreneur or investor whose main objective is to obtain good return for investments. The entrepreneur must accomplish all the foreseen (and unforeseen) steps required to implement a project for a defined period of time (concession period, life cycle) to obtain satisfactory results. The environmental factor represents the view of organized society (non governmental organizations) and authorities (environmental licensing, for instance). These agents oppose to actions that result in environmental degradation and ensure compliance with the legislation. For the social factor, a project causes positive and negative effects to the population in the influence area. The effects range from impacts to economic activities (fishing, agriculture, tourism) to quality of life (air and water pollution, noise). A positive effect, for instance, is the generation of jobs. The political factor reflects the government view through the political class. It is characterized by policy decisions that influence the activity of the enterprise. This is an important agent since political decisions determine how the whole process may occur. Despite the importance of this agent, their actions are not completely independent, because the government is influenced by organized society that has national or international interests. In addition, there must be compliance with the law.

\section{Method}

The technical-economic, environmental, social and political factors have a number of characteristics defined as analysis elements, attempting to globally characterize each factor. Through the definition of a limited number of analysis elements, weighted according to their importance within the context of a factor, it is possible to feed the proposed tool and get practical results to be processed and interpreted. Various elements are shown which are valued by two types of weighting: 1) alternative for each analysis element and 2) weight of each analysis element. Boarati (2003) comments that these two criteria allow each element to be evaluated according to the options available, ranging from the best (excellent) to the worst (unsatisfactory) alternative. These alternatives are considered by percentage values shown in Table 1.

Table 1 - Alternative for each analysis element. Source: Boarati (2003).

\begin{tabular}{lllll}
\hline & $\begin{array}{l}\text { Unsatisfactory } \\
\text { Alternative }\end{array}$ & $\begin{array}{l}\text { Regular } \\
\text { Alternative }\end{array}$ & $\begin{array}{l}\text { Satisfactory } \\
\text { Alternative }\end{array}$ & $\begin{array}{l}\text { Excellent } \\
\text { Alternative }\end{array}$ \\
\hline $\begin{array}{l}\text { Percentage } \\
\text { Valuation }\end{array}$ & $25 \%$ & $50 \%$ & $75 \%$ & $100 \%$ \\
\hline
\end{tabular}

The different analysis elements in each factor were used to characterize the most important aspects treated in the study, for the numerical valuation and the consequent complete cost analysis of the alternatives. According to Boarati (2003), due to the innumerable differences between the elements they do not receive the same valuation in the qualitative analysis. The differentiation is needed to avoid distortions that may affect the valuation of the elements. For instance, the weight of the element "total cost" (A) is higher than the weight of the element "maintenance" (B), because for the environmental factor the effect of $(A)$ is greater. Because they are equally important, each factor must obtain the maximum of 100 points, and from the sum of the four factors there will be, theoretically, a maximum valuation of 400 points for each project (for example, mode of transport).

\subsection{Calculations}

Calculations are done by Equation (1):

Where:

$$
\text { Element } \mathrm{i}=\sum_{\mathrm{i}=1}^{\mathrm{n}} \text { Element } \times \mathrm{N}
$$

$\mathrm{N}=$ alternative (\%). In the numerical application

Alternative (N): Unsatisfactory (25\%); Regular (50\%); Satisfactory (75\%); Excellent (100\%). 
Weight of element: $(A=$ maximum importance $),(B=2 / 3$ of maximum importance $)$ and $(C=1 / 3$ of maximum importance). The numerical values may be used: $A=300, B=200$ and $C=100$. The maximum possible valuation is 100 .

KFC (Considered Factor Constant) - Equation (2):

Where:

$$
\mathrm{KFC}=\left(\frac{300 \times \mathrm{X}+200 \times \mathrm{Y}+100 \times \mathrm{Z}}{100}\right)
$$

$\mathrm{X}, \mathrm{Y}$ and $\mathrm{Z}=$ number of occurrence of the factor weight.

Element valuation - Equation (3):

Element valuation $=\left[\frac{\text { peso }(\mathrm{A}, \mathrm{B}, \mathrm{C})}{\mathrm{KFC}}\right]$. Alternative $\mathrm{N}$

\section{Case study}

The case study area comprises the territory of the state of Mato Grosso do Sul. In July 2012, there were shortages of fuel, gasoline and diesel. Several gas stations ran out of the products, forcing Petrobras to trigger alternative emergency supply by roadways, resulting in higher costs. Therefore, to estimate the energy needs of the region arising from petroleum products, it is necessary to analyse the volume consumed. According to Rigolin (2007), documents of the Planning Secretary of Mato Grosso do Sul (base year 2004) recorded an annual consumption of energy resources of oil in the order of 1,264,904 tons. For the year 2015 it is planned a corresponding value of 2.475 million tons. The demand for petroleum products is expected to double in the next twenty years. Therefore, the ideal mode of transport to supply Petrobras Secondary Base in Campo Grande, state of Mato Grosso do Sul, should be established. Transport mode alternatives of petroleum products are evaluated, and duct is compared to rail transport.

\subsection{Duct transport mode}

The assessment comprises the section of pipeline originating at Paulinia Refinery, in the Southeast state of Sao Paulo, to Campo Grande, MS. For the construction of this duct, several factors that weigh in the work final value can be virtually eliminated, because the Bolivia-Brazil pipeline (GASBOL) already exists in that path. In this case, the easement is open, facilitating the movement of equipment and personnel. The environmental impact report is completed, lacking just a few adjustments to the approval of the new pipeline parallel to GASBOL. In summary, for the technical-economic evaluation of the new duct, the relevant factors are the cost of materials, installation and workmanship. The opening being done significantly reduces costs and diminishes the construction time in about two years. Due to cost reduction, there may be return on investment in about six years Rigolin (2007). Table 2 shows the cost of building a pipeline for comparison.

Table 2 - Cost to build a pipeline. Source: own calculations based in Rigolin (2007).

\begin{tabular}{cl}
\hline Quantity & Cost (US\$) \\
\hline $\begin{array}{c}750,000 \mathrm{~m} 3 \text { of } 12 \text { inch diameter } \\
\text { pipeline }\left[{ }^{1}\right]\end{array}$ & $126,000,000.00$ \\
\hline $\begin{array}{c}\text { Estimate of } 10 \% \text { for lift valves } \\
\text { and pumps }\end{array}$ & $12,600,000.00$ \\
\hline Total & $138,600,000.00$ \\
\hline
\end{tabular}

On the other hand, the operational cost of the pipeline is minimal compared to the construction cost and operating range of values, being crucial to the balance of the invested amounts. Furthermore, because pipeline transportation is continued, the effective velocity, transformed into capacity, results in high flow rates. As in Beims and Santos (2004), the operating cost of pipeline transportation ranges from 10 to 15 dollars per 1,000 m3.ku.

To assess the environmental impacts, greenhouse gas emissions have higher weight due to displacement and operation of the machines responsible for duct installation, and when operating, atmospheric emissions caused by power pump installed along the path can be considered a causative average pollution index. In the social dimension, the analysis considers the number of new temporary jobs created for duct works, the benefits derived from the entry of new royalties and taxes paid to local governments, and the effects of environmental imbalance to the social environment (Rigolin, 2007).

\subsection{Railroad alternative}

There is a railway in operation, therefore, costs of implementing the pathway can be discarded. The maintenance of the infrastructure is considered in operating costs associated with the contract for concession by the Federal Government to a private company. A frequent maintenance of the train wagons should be performed, however, since most parts are national, the maintenance index is low. According to Rigolin (2007), the composition assembly time depends on the number of cars required to transport the total volume. For this case, a two year period is adopted with a turnaround time of 10 years.

With capacity of $103 \mathrm{~m} 3$, the cost of each car is approximately US\$140,000.00 (estimated). Each locomotive costs about a million dollars (Taboada, 2004 cited by Rigolin, 2007). Demand forecast volume of derived products for 2025 is 2.4748 million, which is equivalent to 2,918,394.80 m3. To meet the demand of 5,000 m3 per day, two trains with 150 wagons and 4 locomotives each should be used, carrying ethanol in return. Table 3 illustrates the costs mentioned. Moreover, according to Beims and Santos (2004), the operating cost of rail transport runs around 15-30 dollars per 1,000 TKU.

Table 3 - Costs of two trains for the transport of petroleum products. Source: Rigolin (2007).

\begin{tabular}{ll}
\hline Units & Cost (US\$) \\
\hline $\begin{array}{c}\text { 8 locomotives } \\
\text { 300 tank }\end{array}$ & $8,000,000.00$ \\
wagons & $42,000,000.00$ \\
\hline Total & $50,000,000.00$ \\
\hline
\end{tabular}

For the environmental dimension, moderate pollution and emission of greenhouse gases occur because trains are equipped with diesel-electric locomotives. There is no water pollution, and because the railway already exists there is no soil pollution resulting from the construction of new railways. The risks of exposure to exchange rate fluctuations are low 
due to the technology applied to rail be practically national. It is expected that there will be government support, because fuel shortage brings a very negative political dividend. Also, since railway is a reality, there may not be public opposition.

\subsection{Results}

Tables 4, 5, 6 and 7 show the results obtained by applying the complete cost analysis for ducts and rail transport modes, showing the factors considered, their respective weights and final valuation alternative in order to obtain the total score. Figure 1 illustrates the valuation graphs obtained in the analysis, showing greater values for ducts. The only greater factor for rail is the political, which was already clearly expected.

Table 4 - Analysis results for technical-economic factor

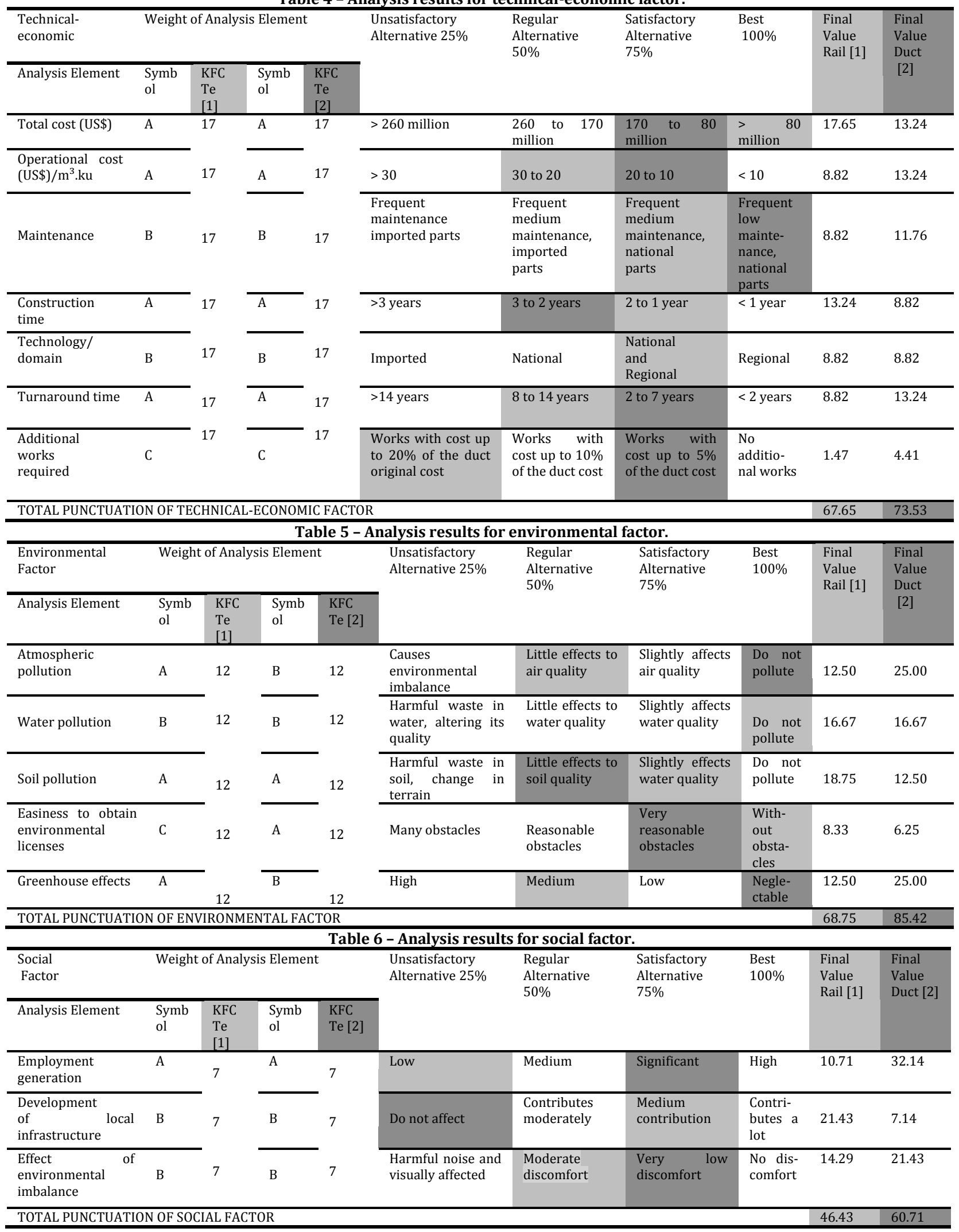


Table 7 - Analysis results for political factor.

\begin{tabular}{|c|c|c|c|c|c|c|c|c|c|c|}
\hline \multirow{2}{*}{$\begin{array}{l}\text { Political } \\
\text { Factor } \\
\text { Analysis Element }\end{array}$} & \multicolumn{4}{|c|}{ Weight of Analysis Element } & \multirow{2}{*}{$\begin{array}{l}\text { Unsatisfactory } \\
\text { Alternative } 25 \%\end{array}$} & \multirow{2}{*}{$\begin{array}{l}\text { Regular } \\
\text { Alternative } \\
50 \%\end{array}$} & \multirow{2}{*}{$\begin{array}{l}\text { Satisfactory } \\
\text { Alternative } \\
75 \%\end{array}$} & \multirow{2}{*}{$\begin{array}{l}\text { Best } \\
100 \%\end{array}$} & \multirow{2}{*}{$\begin{array}{l}\text { Final } \\
\text { Value } \\
\text { Rail [1] }\end{array}$} & \multirow{2}{*}{$\begin{array}{l}\text { Final } \\
\text { Value } \\
\text { Duct } \\
{[2]}\end{array}$} \\
\hline & $\begin{array}{l}\text { Symb } \\
\text { ol }\end{array}$ & $\begin{array}{l}\mathrm{KFC} \\
\mathrm{Te} \\
{[1]}\end{array}$ & $\begin{array}{l}\text { Symb } \\
\text { ol }\end{array}$ & $\begin{array}{l}\mathrm{KFC} \\
\mathrm{Te} \\
{[2]}\end{array}$ & & & & & & \\
\hline $\begin{array}{l}\text { Risk of currency } \\
\text { exposure }\end{array}$ & B & 8 & B & 8 & $\begin{array}{l}\text { Imported } \\
\text { technology }\end{array}$ & $\begin{array}{l}\text { Mixt } \\
\text { technology; } \\
\text { Partial risk }\end{array}$ & $\begin{array}{l}\text { National } \\
\text { technology; } \\
\text { Partial risk }\end{array}$ & $\begin{array}{l}\text { National } \\
\text { techno- } \\
\text { logy; } \\
\text { Low risk } \\
\end{array}$ & 21.43 & 25.00 \\
\hline $\begin{array}{l}\text { Government } \\
\text { support }\end{array}$ & A & 8 & A & 8 & $\begin{array}{l}\text { No government } \\
\text { support }\end{array}$ & Indifferent & $\begin{array}{l}\text { Medium } \\
\text { support }\end{array}$ & $\begin{array}{l}\text { High } \\
\text { support }\end{array}$ & 32.14 & 28.13 \\
\hline $\begin{array}{l}\text { Population } \\
\text { opposition }\end{array}$ & $\mathrm{A}$ & 8 & $\mathrm{~A}$ & 8 & $\begin{array}{l}\text { Population } \\
\text { opposition }\end{array}$ & $\begin{array}{l}\text { Low } \\
\text { opposition }\end{array}$ & $\begin{array}{l}\text { Very low } \\
\text { opposition }\end{array}$ & $\begin{array}{l}\text { Total } \\
\text { support }\end{array}$ & 21.43 & 18.75 \\
\hline TOTAL PUNCTUA' & ON OF I & LITIC & $\overline{\text { FACTOR }}$ & & & & & & 75.00 & 71.88 \\
\hline
\end{tabular}

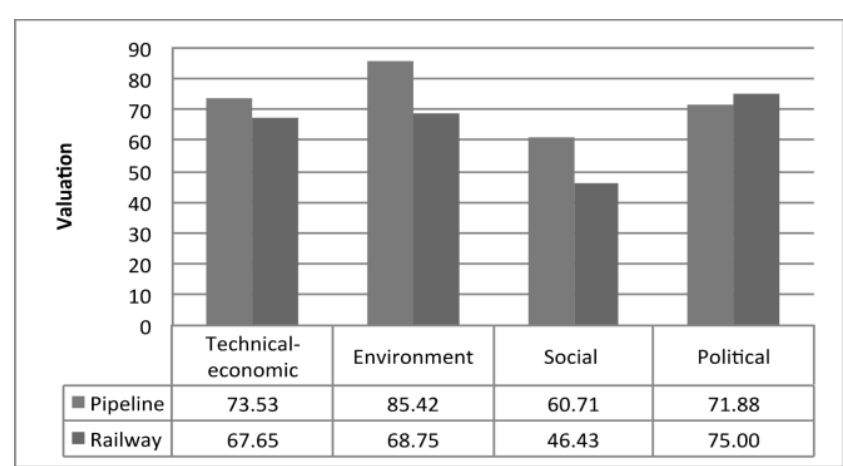

Figure 1 - Valuation graphic per factor and transport mode. Source: own calculations.

\section{Conclusion}

The objective of this research is to evaluate ducts and railway transport modes using the Complete Cost tool to find the best alternative for the transport of petroleum products. The environment, the users, the social implications and policy decisions are of great importance for the analysis. The methodology considers all the elements involved in an evaluation process. Only aspects related to investment, construction, equipment acquisition and financial return have been traditionally considered, shown inadequate. The Complete Cost tool is part of the Integrated Planning Resources (PIR) methodology, and it may be applied to problems expressed by environmental, political, social and technical-economic dimensions by the use of technical systemic analysis and mathematical tools (Rigolin, 2013).

The evaluation of the transport alternatives only by financial cost of construction shows the railway as the best alternative for the transportation of petroleum products, with a cost of US $\$ 50,000,000.00$ compared to US $\$ 138,600,000.00$ for the pipeline mode. However, the evaluation by the Complete Cost tool, which includes the analysis of technicaleconomic, environmental, social and political factors, shows that the most adequate mode is the pipeline with the highest valuation factors. Despite the construction costs, the complete cost analysis shows that ducts are more advantageous with the highest values for the factors considered in the analysis (291,54 points) versus the railway (257,83 points). Therefore, this study contributes to a more effective evaluation and discussion about the important aspects to be evaluated in making a choice for the most sustainable transport mode.

The analysis model provided the indication of the most sustainable mode of transport. The tool can be used in decision making regarding the definition of which is the best project to be implemented. However, it is recommended that the PIR methodology should be addressed in a future study so that the alternative valuation for the analysis elements will be more specific, arising from a more detailed evaluation as shown in Rigolin (2013).

\section{References}

Beims, M. I., \& Santos, S. A. (2004). Reality for contemporary Brazilian logistics freight transport: air, duct, train and roadway (Master's dissertation). Federal University of Santa Catarina, Florianopolis, Brazil.

Boarati, J. H. (2003). Model for evaluation of weighted hydroelectricity and thermoelectric natural gas by the complete cost analysis (Master's dissertation). University of Sao Paulo, Sao Paulo, Brazil.

Boarati, J. H. ; Shayani, R. A. ; Udaeta, M. E. M. ; Galvão, L. C. R. (1999). Comparative analysis of the hydric electric generation versus natural gas generation. Revista Brasileira de Energia, Rio de Janeiro, v. 7, p. 23-34.

Rigolin, P. H. C. (2007). Comprehensive evaluation of energy modes of transportation of natural gas even as secondary energy (Master's dissertation). University of Sao Paulo, Sao Paulo, Brazil.

Rigolin, P. H. C. (2013). Development of a system to classify energy resources supply and demand based on the calculation and assessment of the full potential of energy resources within the integrated resource planning (Doctoral thesis). University of Sao Paulo, Sao Paulo, Brazil.

Rigolin, P. H. C.; Udaeta, M. E. M.; Cicone Jr, D. ; Grimoni, J. A. B. (2011). Full cost account for integrated energy resources planning using the analytic hierarchy process. Proceedings of the International Symposium on the Analytic Hierarchy Process for Multicriteria Decision Making, v. 1, p. 40.

Silva, P. R. (2004). Maritime oil and oil in the Brazilian coast: structure and environmental implications (Master's dissertation). Federal University of Rio de Janeiro, Rio de Janeiro, Brazil.

Soares, A. C., Leal, J. E., \& Azevedo, I. R. (2003). Diagnosis of the distribution network of oil products in Brazil and its representation in a GIS. Proceedings of the XXIII National Meeting of Production Engineering - ENEGEP 2003 ABEPRO 1, Ouro Preto, Brazil. 